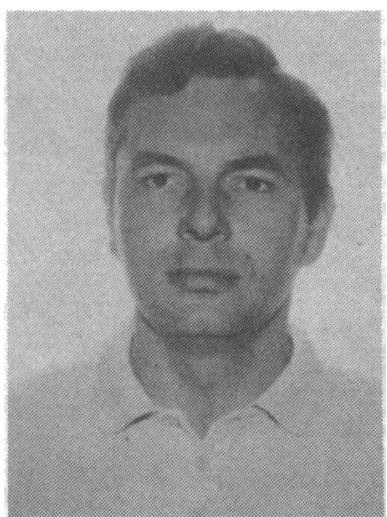

B. Krobs

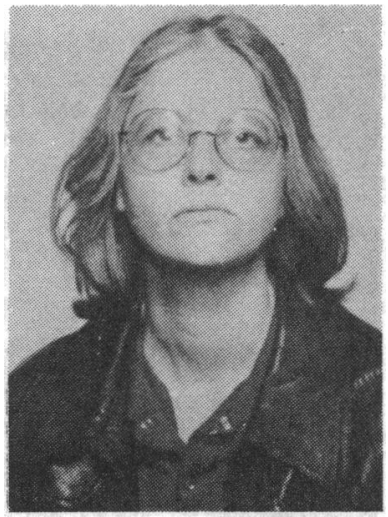

L. K. Gron

\title{
SIMULTANEOUS DORSAL DISLOCATION OF BOTH INTERPHALANGEAL JOINTS IN A FINGER
}

\author{
B. KREBS, MD and L. K. GR $\emptyset N, M D$
}

Dept. of Orthopaedic Surgery, The University Hospital Arhus, 8000 Arhus C, Denmark

\begin{abstract}
Following simultaneous dorsal dislocation of both interphalangeal joints of a finger, attention must be paid to the risk of a long period of recovery because of the severity of the lesion. Approximately one year after such an accident to a footballer arthrodesis was performed on the proximal interphalangeal joint, as the patient was still suffering from constant pain in the finger.
\end{abstract}

Key words: Double dislocation, Dislocation of a finger, Sport injury.

\section{INTRODUCTION}

Traumatic injury of a finger often causes dislocation of the distal or the proximal interphalangeal joint, while double dislocation of a single finger is very seldom described (Bartels, 1874; Sayre, 1892; Von Scholle, 1931; Schorcher, 1932). Yet, during recent years a few cases have been described (Nathan and Schlein, 1973; Stock \& Weber, 1974). The aetiology of the trauma is most often ballgames, and Ikpeme (1977) has described brilliantly the mechanism of the injury. The cases described earlier have been relatively uncomplicated, but in view of the severity of the lesion we describe, double dislocation is more serious regarding prognosis than other authors have found.

\section{Correspondence and reprint requests to:}

Dr. Borge Krebs

Dept. of Orthopaedic Surgery

The University Hospital of Arhus

DK-8000 ARHUS C

Denmark

\section{CASE REPORT}

A 24 year old man injured his right little finger while playing football. The ball hit the tip of the finger; this immediately resulted in pain and deformity. At the hospital clinical examination and $X$-ray films showed dorsal dislocation of both interphalangeal joints. There were small chip fractures dorsal and volar to the joints, and a sign of lesion of the volar fibrocartilage and the dorsal capsule of the proximal joint and a lesion of the capsule of the distal joint. The nerves and vessels of the finger were not damaged.

After the dislocations were reduced, the examination revealed no sign of laxity in the joints, and the finger was immobilised on a Böhler splint, in a position as recommended in 1976 by Barfod for three weeks. After this period active exercises were started, and the patient was regularly examined in the department.

When the finger was examined 4 months after injury 


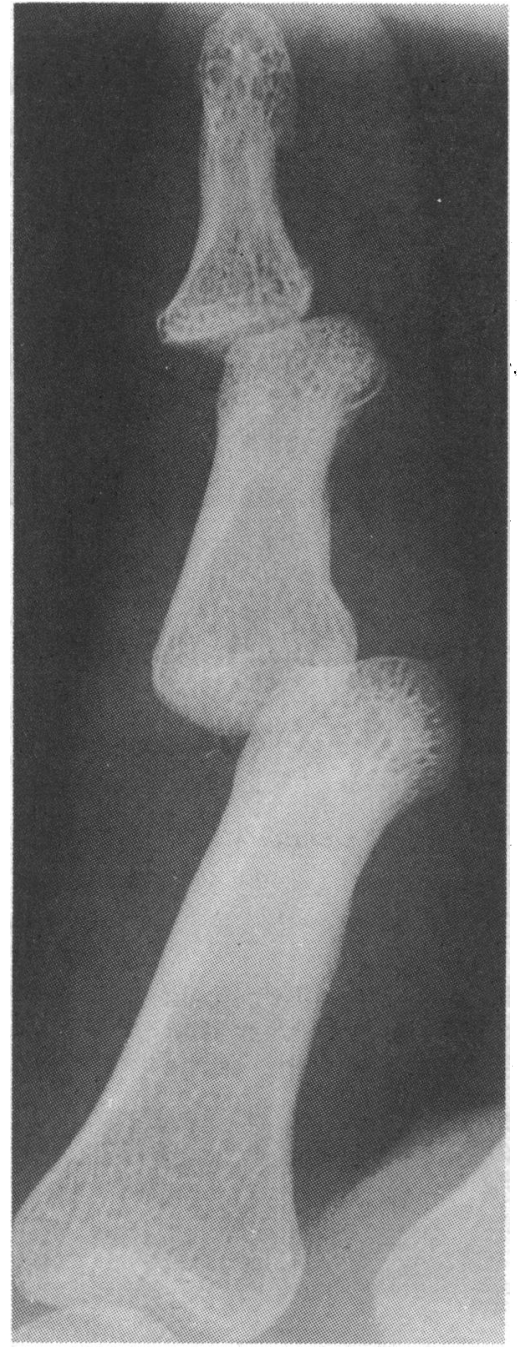

Fig. 1-A: Antero-posterior roentgenogram.

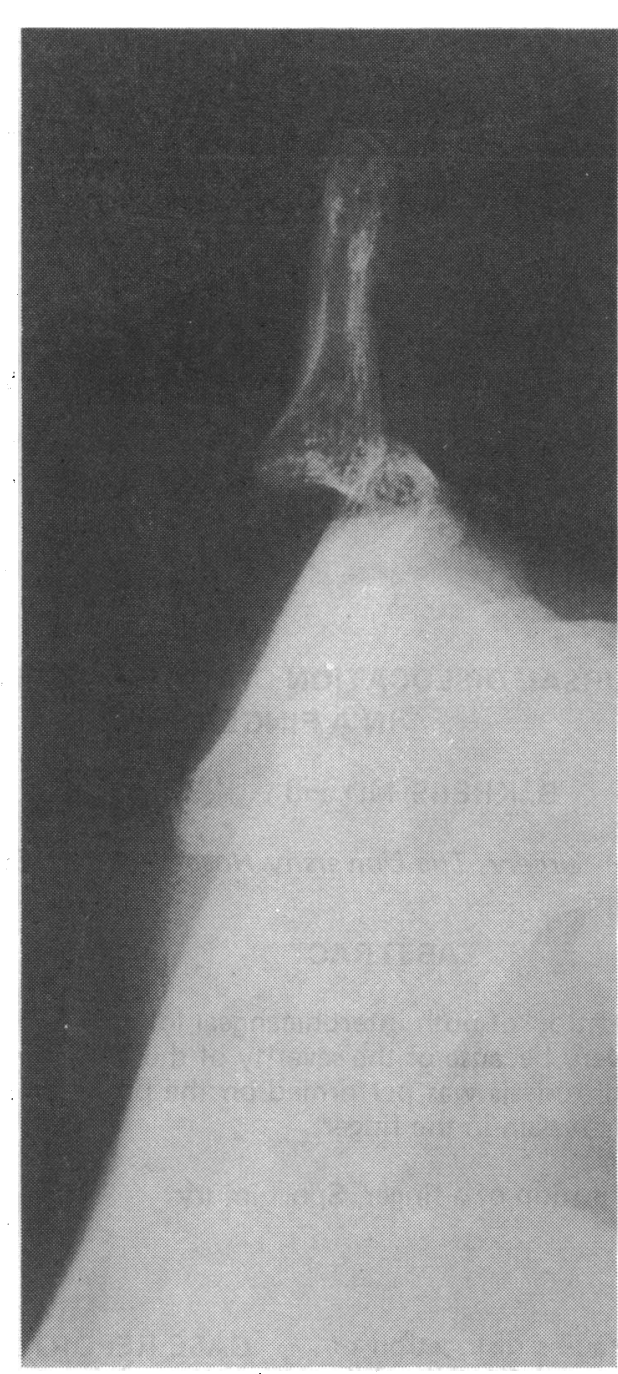

Fig. 1-B: Lateral roentgenogram.

Figs. 1-A, 1-B and 1-C: Roentgenograms showing the simultaneous dorsal dislocation of both interphalangeal joints of a finger.

there was still moderate swelling of the joints, and pain when the finger was moved. The mobility of the metacarpophalangeal joint was normal, while flexion of the proximal joint was reduced to a range of $5^{\circ}-50^{\circ}$, and flexion of the distal joint to $5^{\circ}-15^{\circ}$. Nine months after the accident there was no change of the mobility, but the patient was suffering from severe pain on any movement of, or touch to the finger. It was decided to perform arthrodesis on the proximal joint. There was no sign of a Sudeck's atrophy or of osteoporosis of the bones.

\section{DISCUSSION}

In published articles of recent date a few cases of double dislocation are described, and they are all characterised by an uncomplicated course. Ikpeme (1977) describes a case of a 33-year-old man, where there was complete recovery four months after the trauma. In a case of a 28 year old man full recovery was obtained after two months (Weseley et al, 1978), yet Krishnan (1979) describes a case of a 32 year old man with a rather long period of disability. The finger was immobilised for four
Fig. 1-C: Post-reduction lateral roentgenogram.

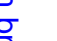


weeks, but the author does not specify the position of the finger during immobilisation. Two years later he states that the condition is satisfactory. Nathan and Schlein (1973) find that there are no problems with the treatment, and that their patients do well. The described lesions in our patient, with chip fractures at the site of the proximal and distal joints, show the severity of the injury. We find that a double dislocation should be regarded as far more serious than a single dislocation when considering the prognosis.

\section{REFERENCES}

Barfod, B., 1976 “Primær behandling af håndlæsioner". F.a.d.I., Århus, 3 ed.; 24.

Bartels, M., 1874 "Traumatische Luxationen". Arch.Chir. 16: 645.

Ikpeme, J. O., 1977 "Dislocation of both interphalangeal joints of one finger". Injury 9: 68-70.

Krishnan, S. G., 1979 “Double dislocation of a finger”. Am.J.Sports Med. 7: 204-205.

Nathan, F. F. and Schlein, A. P., 1973 “Multiple dislocations of a single finger". Hand 5: 52-54.

Sayre, L. A., 1892 "Simultaneous dislocation of the first and second phalangeal joints of the middle finger". N.Y.Med. J. 56: 379.

Sch8̈rcher, F., 1932 "Ausrenkung zweier Gleider an Demselben Finger". Chirurg 4: 150.

Stock, H. J. and Weber, H., 1974 "Zweifache Luxation an einem finger". Beitr.Orthop.Traumatol. 21: 746-747.

Von Scholle, W., 1931 “Verrenkung zweier Gleider an dem gleichen Finger”. Munch.Med.Wochenschr. $78: 1337$.

Weseley, M. S., Barenfeld, P. A. and Eisenstein, A. L., 1978 "Simultaneous dorsal dislocation of both interphalangeal joints in a finger". J.Bone Jt.Surg. 60-1: 1142.

\section{BOOK REVIEW}

Title: CASH'S TEXTBOOK OF ORTHOPAEDICS AND RHEUMATOLOGY FOR PHYSIOTHERAPISTS

Editor: P. A. Downie

Publisher:

Faber and Faber

Price: $£$ 7.95 Soft cover

At long last a textbook to replace my beloved, but alas, outdated "Cash's 2 textbooks on Medical and Surgical Conditions for Physiotherapists". These were invaluable in my training, and I am sure the new "Cash" will be the same to newly qualified and practising physiotherapists.

The section on mechanics of lower limb orthoses is superb. It is also good to see that examination and assessment is covered, also principles of manipulation.

Clear diagrams throughout, and the book is well presented and easy to read. I enjoyed reading it!

Congratulations to the Sports Medicine section and Sandy MacLaren's "Maxercises". This will cause comment from many, but we need comments and "rethinks" of our training programmes. We have got to update.

Yes! A superb book, to gain pride of place in any physiotherapist's library. Only one adverse comment. Please not a crêpe bandage for a Robert Jones bandage. That was the worst sin in all my orthopaedic training, as a nurse and physiotherapist.

Paula Willcock 